\title{
Público y cine en España. Problemas de identidad y marca para un cine propio
}

\author{
Emilio C. GARCía FERNÁNDEZ \\ Universidad Complutense de Madrid \\ avia@ccinf.ucm.es \\ Maribel ReYes MoREno \\ Universidad Complutense de Madrid \\ maribelreyes@telefonica.net \\ Jorge Clemente Mediavilla \\ Universidad Complutense de Madrid \\ jclemen@ccinf.ucm.es
}

Recibido: 3 de julio de 2013

Aceptado: 17 de diciembre de 2013

\begin{abstract}
Resumen
El cine español ha sufrido una serie de vicisitudes a lo largo de su historia que han marcado tanto su producción, como el desarrollo de una industria solvente y sólida, y la valoración que de la misma ha hecho el público de cada época. Las relaciones que se han establecido entre el ciudadano español en la oferta cinematográfica realizada no han sido las más adecuadas para que la convivencia fuera eficaz. Desde la profesión no se ha hecho el esfuerzo por transmitir una imagen eficaz que pudiera consolidar la marca necesaria para el reconocimiento de la industria. Todas las partes intervinientes en el desarrollo de esta industria han sobrevivido a las novedades sin plantearse seriamente cómo afrontar cada uno de los retos que se le fueron presentando. El resultado no es otro que, en el momento presente, han de involucrarse en recuperar el tiempo perdido si realmente quieren seguir manteniendo activo el negocio. Posibilidades, todavía las hay, pero es necesario el empeño manifiesto de las instituciones, profesionales y público español.
\end{abstract}

Palabras clave: España, Cine, Público, Industria, Marca, Publicidad

\section{The Public and the Cine in Spain. Issues of identity and brand}

\begin{abstract}
Spanish cinema has suffered a series of troubles along its history. They have determined its production, along with the development of a solvent and solid industry. This trajectory has also had influence in the assessment of the audience. The relationships developed between the Spanish audience and the cinema offer haven't favored their coexistence. From the profession, the effort to transmit an effective image hasn't achieved to consolidate the necessary branding for the recognition of the industry. All the parts involved in the development of this industry have survived the novelties without seriously consider how to deal with each one of the new challenges. At present, the result is that all those parts involved must join to update the business to keep it active. There are possibilities yet, but a clear determination is needed from the institutions, professionals and the Spanish audience.

Keywords: Spain, Cinema, Audience, Industry, Branding, Advertising

\section{Referencia normalizada}

GARCÍA FERNÁNDEZ, Emilio C.; REYES MORENO, Maribel; y CLEMENTE MEDIAVILLA, Jorge (2014): "Público y cine en España. Problemas de identidad y marca para un cine propio". Estudios sobre el Mensaje Periodístico. Vol. 20, Núm. 2 (julio-diciembre), págs.: 695-718. Madrid, Servicio de Publicaciones de la Universidad Complutense.
\end{abstract}

Sumario: 1. Introducción. 2. El punto de partida. 3. Argumentos necesarios. 4. Problemas de identidad. 5. Difusión de la imagen. 6. Conciencia de marca. Un objetivo necesario. 7. Conclusiones. 8. Referencias bibliográficas. 


\section{Introducción.}

Reconocemos la existencia de algunos acercamientos al estudio de las relaciones existentes entre el cine y su público en España. Acercamientos que nos hablan, entre otros, desde los documentos, el modelo de vida, los rasgos sociales, económicos y culturales, la crisis emocional de un grupo humano o el rechazo a modelos de conducta y valores instituidos que fueron perfilando el ser de un ciudadano a lo largo de su existencia (Montero y Cabeza, 2005; Montero y Paz, 2011). Sin duda, son aportaciones que redundan en el conocimiento de los intereses que movieron a un colectivo de individuos, el público variopinto transformado en espectador selectivo a la hora de asistir, con más o menos frecuencia, a una determinada sala de cine en busca de un programa espectacular, entretenido o llamativo desde una perspectiva individual.

También sobre todo lo relacionado con la información y propaganda, con la visión ofrecida en todo tipo de películas sobre España, los españoles, su cultura y tradiciones, su manera de ser y de expresarse. Son muchas las cuestiones que se han abordado en estudios, algunos muy notables, que dan luz a pasajes de un medio de comunicación, información y entretenimiento que se ha ido convirtiendo con el paso del tiempo en referencia social de indiscutible valor.

Precisamente, desde hace ya algunos años el interés por estos temas (García Fernández, 1985, 2002) ha generado otra línea de trabajo e investigación en España centrada en la relación directa que se establece entre el público y su cine. La identidad, la marca, como nexo de unión entre el productor y creador y el receptor, mirando más allá de lo que pueda ser la imagen, la promoción y publicidad del producto objeto de relación.

En este sentido, los problemas comunicativos que se vienen detectando en el cine español apenas se han abordado (García Fernández, 2004: 69). Es más, se mantienen al margen de otros intereses que son los que más preocupan a los profesionales de la industria; como, por ejemplo, su propia supervivencia industrial o creativa, olvidándose de una realidad constatable y contagiosa que es la que ha llevado al cine español al punto en que se encuentra: distanciado de su receptor inmediato. Intereses que llevan emparejados aquellos que impulsa la crítica cinematográfica defendiendo siempre posturas contrarias a los intereses generales, lo que no favorece la existencia de una oferta complementaria.

El debate más reciente se ha generado desde el seno de la Academia de Cine ${ }^{1}$, intentando el acercamiento a una más que evidente falta de interés del público español por el cine que se hace en España. Y todo eso más allá de algunos éxitos puntuales que alguien quiere aprovechar como indicios de que, todavía, el cine español todavía puede recuperar a su público.

\section{El punto de partida}

El cine español a lo largo de de los últimos 30 años ha perdido su propio mercado. Y lo ha hecho con decisión, a raíz del desarrollo de un modelo de negocio que para nada ha tenido en cuenta a quien lo sostiene realmente. Existen evidencias claras que justifican el comentario, y que tienen que ver con los valores que proporcionan los éxitos de tem-

${ }_{1}$ Academia. Revista del Cine Español. № 191, julio-agosto 2012. pp. 5-21. 
porada, validados por la asistencia a salas de espectadores, la cuota de mercado que tiene anualmente el cine español, y la promoción que se hace de las películas.

El Instituto de la Cinematografía y las Artes Audiovisuales (ICAA), aunque sin una información excesiva, detallada y con perspectiva, proporciona los primeros datos que sirven de ayuda para lo que se pretende. De los primeros cincuenta largometrajes españoles con mayor número de espectadores desde su estreno -y teniendo como fecha de partida la implantación del control de taquilla en 1965- destacan los 23 de los años sesenta, 11 de la primera década del siglo XXI, 9 de los años setenta, 4 de la década de los noventa y 2 de los años ochenta. Es decir, que en los últimos treinta años sólo 18 películas tuvieron un respaldo importante del público español, superando los 2.4 millones de espectadores. Y si centramos nuestra mirada en aquellos filmes que han superado los cuatro millones de entradas, descubrimos que sólo once títulos se sitúan en lo más alto de la lista, y entre los que todavía no estarían los dos grandes éxitos de 2012: Lo imposible, de Juan Antonio Bayona, y Las aventuras de Tadeo Jones, de Enrique Gato. Esto confirma que algo no se está haciendo bien, más allá de los resultados de taquilla.

Otro de los elementos que hay que valorar tras los estrenos y la producción anual es el alcance de los mismos, su proyección en el mercado y la respuesta que tienen del público que asiste a las salas. La cuota de mercado es un indicador claro de cómo evoluciona en cada temporada la oferta cinematográfica y cómo es atendida por el espectador. En el cuadro siguiente ${ }^{2}$ podemos apreciar la evolución en las últimas tres décadas, desde que Pilar Miró es nombrada Directora General de Cinematografía en el primer gobierno socialista (en diciembre de 1982), hasta el momento presente.

\begin{tabular}{|c|c|c|c|c|}
\hline Año & $\begin{array}{c}\mathrm{N}^{0} \text { de películas } \\
\text { totalmente } \\
\text { españolas }\end{array}$ & Coproducciones & $\begin{array}{l}\text { Total de } \\
\text { películas } \\
\text { españolas }\end{array}$ & $\begin{array}{c}\text { Cuota de } \\
\text { mercado (\%) }\end{array}$ \\
\hline 1982 & 118 & 28 & 146 & 22,80 \\
\hline 1983 & 81 & 18 & 99 & 20,40 \\
\hline 1984 & 63 & 12 & 75 & 20,90 \\
\hline 1985 & 65 & 12 & 77 & 16,20 \\
\hline 1986 & 49 & 11 & 60 & 12,40 \\
\hline 1987 & 62 & 7 & 69 & 14,30 \\
\hline 1988 & 54 & 9 & 63 & 11,10 \\
\hline 1989 & 43 & 5 & 48 & 7,69 \\
\hline 1990 & 37 & 10 & 47 & 11,09 \\
\hline 1991 & 46 & 18 & 64 & 11,13 \\
\hline 1992 & 38 & 14 & 52 & 9,63 \\
\hline 1993 & 41 & 15 & 56 & 9,07 \\
\hline 1994 & 36 & 8 & 44 & 7,29 \\
\hline 1995 & 37 & 22 & 59 & 12,27 \\
\hline 1996 & 66 & 25 & 91 & 9,33 \\
\hline 1997 & 45 & 25 & 80 & 13,17 \\
\hline
\end{tabular}

${ }^{2}$ Elaboración propia a partir de los datos de Antonio Cuevas. "Cine \& Teleinforme". N 685 y del ICAA. 


\begin{tabular}{|c|c|c|c|c|}
\hline 1998 & 56 & 19 & 65 & 12,00 \\
1999 & 44 & 38 & 82 & 14,35 \\
2000 & 64 & 34 & 98 & 10,03 \\
2001 & 66 & 40 & 106 & 17,87 \\
2002 & 80 & 57 & 137 & 13,66 \\
2003 & 68 & 42 & 110 & 15,77 \\
2004 & 92 & 41 & 133 & 13,43 \\
2005 & 89 & 53 & 142 & 16,73 \\
2006 & 109 & 41 & 150 & 15,47 \\
2007 & 115 & 57 & 172 & 13,50 \\
2008 & 124 & 49 & 173 & 13,18 \\
2009 & 135 & 51 & 186 & 15,55 \\
2010 & 151 & 49 & 200 & 12,12 \\
2011 & 151 & 48 & 199 & 15,59 \\
$2012 *$ & & & 163 & 17,90 \\
\hline
\end{tabular}

Elaboración propia* Datos al 25 de diciembre de 2012.

Con relación a estos datos, conviene recordar que algunas de las cuestiones que llevan a la pérdida de mercado son, básicamente: el fomento de un cine de calidad sostenido por argumentaciones que hablan de la internacionalización de nuestro cine, del valor cultural del mismo y del apoyo de la creación autoral, pensando que esta reorientación cambiaría los gustos del espectador que, siempre desde la perspectiva de un pequeño grupo de profesionales y especialmente arropados por un sector de críticos que vivirán de ello, se mantenía anclada en modelos temáticos y estéticos ya obsoletos.

Evidentemente, bajo este ideario hay un problema de fondo que es el que se proyecta sobre el modelo de producción desarrollado desde los primeros años ochenta: una producción dependiente, auspiciada por el Gobierno de turno, que se mostrará dócil o díscola en función de quien esté al frente de la política de Estado. No hay duda de que se acometen proyectos de notable factura artística pero también es evidente que no alcanzan la dimensión social deseada. La causa, sin duda, se encuentra en que la convivencia de los modelos industriales y artísticos no ha sido posible desde el primer momento, porque se plantean como antagónicos, no complementarios como hubiese sido lo más razonable.

Y como cabe esperar, las imposiciones generan rechazo y éste un enfrentamiento de posturas que resultan irreconciliables. De nada sirve que la crítica en medios diversos insista en las virtudes de una película que nadie ve, como tampoco ayuda el hecho de que dicha película sea premiada en numerosos lugares del mundo si su estreno en España ni se ha conocido. Tampoco es posible entender cómo una película que no se ha estrenado puede convertirse en representante de la producción anual en el camino a los Oscar. Las opiniones que todas estas iniciativas generan en la calle jamás son escuchadas por los profesionales que, una y otra vez, siguen haciendo lo mismo.

El punto de partida de esta investigación se encuentra en las actitudes de una industria y sus profesionales, en los modelos que quieren imponer a los espectadores y en las ausencias identitarias que difícilmente ayudarán a la consecución de unos objetivos empresariales claros y determinantes. 


\section{Argumentos necesarios}

La evolución del cine español proporciona suficientes argumentos como para entender qué hacer frente al público que recepciona una obra. Es decir, de qué manera la industria genera recursos y obras suficientes para convertirse en polo de atracción de las miradas y curiosidades personales.

Lo más relevante para el sostenimiento del espectáculo es que el espectador disponga de los recursos mínimos necesarios como para asistir con frecuencia a las proyecciones que se ofrecen. Además, esa base económica también favorecerá que dicho espectáculo se expanda por las ciudades gracias al apoyo publicitario y promocional que llevan a cabo los medios de comunicación. Al mismo tiempo, no se debe olvidar que cada sociedad ha tenido acceso a un determinado conjunto de soportes comunicativos que trascendieron del ámbito general para llegar al reducto familiar y potenciar así, en sucesivas actuaciones, el altavoz por el que se difundían las novedades cinematográficas; es decir, los espectadores se van adaptando a los nuevos intereses. Los medios que van llegando a la sociedad (teléfono, radio, televisión, video, ordenador, Internet, videojuegos, teléfono móvil, etc.,) modifican hábitos, costumbres y el modo de actuar y comunicarse de la propia sociedad- (Vargas Llosa, 2012: 208).

El punto de partida fue la improvisación, la curiosidad por lo novedoso; aquellos emprendedores que llegaban desde otros negocios dan pasos ocurrentes hacia un nuevo destino: la producción de películas. Es decir, que acuden a los recursos familiares y sus propios negocios se ponen al servicio de la nueva iniciativa empresarial. Las aventuras, en cualquier caso, fueron numerosas en este primer periodo, y los resultados no tan favorecedores como se prometían para la inmensa mayoría.

El problema principal lo tenían sobre el modelo de producción que desarrollaban y el contraste que ofrecía en la pantalla ante los estrenos de películas extranjeras. Desde el primer momento la competencia fue muy fuerte y en la misma jugaron un papel muy importante los distribuidores y exhibidores que vieron desde el primer momento que el cine español no atraía al público en número suficiente como para apostar por él en las programaciones. Estos síntomas ya indican que algo falla en el modelo de producción; síntomas que tienen más que ver con la improvisación y la falta de claridad a la hora de elegir asuntos que llevar a la pantalla o personajes que puedan resultar atractivos y relevantes para el lanzamiento de las obras. Una empresa, un sello editorial -en el argot de la época-, un director artístico o un cuadro de actores se pueden hacer notar, pero hay que saber en qué se fija el espectador, cuáles son sus preferencias, qué temas le interesan más... y, posteriormente, ofrecerle un producto bien elaborado. Las productoras consolidan su imagen sobre un conjunto de películas en las que se aprecia un gran desequilibrio y en el que no se contempla una coordinación precisa para arropar la iniciativa con productos de notables niveles creativos y fórmulas comerciales complementarias.

La envergadura creativa y de producción que se aprecia en el cine estadounidense y en el alemán desde la segunda década del siglo XX, por poner sólo dos ejemplos, no contagia a la industria cinematográfica que existe en España, sobre todo porque los recursos infraestructurales existentes -productoras, Estudios, laboratorios, etc.- no permiten desarrollar iniciativas similares y porque, también, la dimensión creativa 
muestra evidentes lagunas. El espectador es consciente de todo esto. Ve las carteleras en las entradas de las salas de cine y decide entrar o no a ver un determinado título.

El encanto, atractivo y los reclamos con los que se sustentan las películas extranjeras no existen en la mayoría de las películas españolas. Y cuando hay que administrar los exiguos recursos económicos familiares el espectador se ve obligado a elegir sabiendo, además, que el resto de ciudadanos habla de determinadas películas en los lugares de encuentro, en la calle, por el barrio, etc. Las diversas iniciativas de cierta envergadura que se impulsan durante la década de los años veinte-como, por ejemplo, la productora Atlántida- se presentan, a priori, como los pilares necesarios para que el cine español levante la cabeza. No obstante, la inconsistencia del mercado para el producto propio -el espectador estaba más interesado por el cine extranjero ya en esta época- y la falta de apoyo del sector de exhibición -ya controlado por la industria foránea, especialmente la estadounidense- hacen que los retos planteados por algunas productoras, aunque con demasiada alegría y escasa profesionalidad empresarial, no alcancen los objetivos previstos y generen un torrente de fiascos que agravan más la situación. (Guback, 1980: I, 88)

La implantación del sonido no despierta curiosidad en el mercado español hasta que pueda asegurar su pervivencia. Los experimentos iniciales, la precariedad de los primeros rodajes con sonido dan paso a una industria activa y sólida capaz de afrontar con eficacia los nuevos retos. La actividad de firmas como Cifesa (Gubern, 1977) y Filmófono (Fernández Colorado y Cerdán, 2007) se ve favorecida por una situación del mercado de exhibición muy lamentable, puesto que tarda demasiados años en incorporar la tecnología apropiada para las películas sonoras. Salvo en las grandes ciudades, el resto de la población se tiene que conformar con proyecciones mudas. Y en las ciudades más pobladas son muchas las salas que exhiben películas en otros idiomas. Esta circunstancia y que el cine hablado en español -sobre todo la producción propia- sea entendido por todos los espectadores hace que en cuatro años las productoras mencionadas alcancen una importante notoriedad porque sus películas son las más populares del momento, llegando a unos niveles de aceptación, permanencia en cartel y, consecuentemente, de taquilla nunca vistos hasta los días previos a la Guerra Civil.

La popularidad que alcanzan ciertas historias en estos años treinta y la repercusión que logran sus protagonistas ya están indicando que hay un acercamiento entre las películas y los espectadores, quizá porque el idioma y los diálogos ya se sienten cercanos, se siguen sin problemas y permiten disfrutar las situaciones con mas simpatía (Gubern, 1977: 78). Además el Gobierno del momento también cuida de que a las pantallas españolas lleguen los asuntos menos comprometidos, especialmente en la producción extranjera de ficción y no ficción que se pretende exhibir en España (Paz y Montero, 2010).

Y en muchos casos, se comprobará en la inmediata postguerra, dado que estas películas servirán de impulso a la reconstrucción del sector a lo largo de la geografía española. El puente que conecta ambas situaciones lo establece Cifesa, una marca que suscribe sus intenciones en un eslogan que dice "La antorcha de los éxitos", lo que significa que apostará no sólo por las historias más eficaces -siempre dominadas por temas y cuestiones que deben asumir cierto adoctrinamiento político, religioso, so- 
cial y moral- sino, también, por los rostros más populares del momento, señalando con ello que en España también se pueden aplicar modelos de negocio cercanos a los estadounidenses, especialmente en todo lo que concierne al star-system y la explotación de sus producciones sustentada en un red comercial extensa, tanto en España como en países con el mismo idioma. Después llegarán otras firmas que irán ampliando la producción, especialmente Cesáreo González-Suevia Films, que buscarán en los rostros más llamativos el apoyo necesario para rentabilizar sus películas (García Fernández, 2003).

Mucho se ha dicho de un espectador atrapado, dominado por la política existente, permisivo y, sobre todo, sumiso. Cada época se ve inmersa en una serie de circunstancias sociales, políticas y económicas que la señalan y que, desde perspectivas de un análisis posterior, se critican visceralmente (Galán, 1997: 113). Cuando desde ese estudio sólo se hace hincapié en aquellos que buscaron una alternativa de producción y creativa, y se olvidan de que se les permitió hacer lo que hicieron y ellos mismos se aprovecharon de la coyuntura en la que estaba metido el cine del momento, fracasan en el intento de hablar abiertamente del conjunto de situaciones vividas. Es así, también, desde la perspectiva del espectador, que vinculado a un determinado tipo de cine de género - hablemos del cine de "cartón piedra" histórico, de la "españolada" reiterativa y folklórica, etc.-, se ve rodeado de una serie de aportaciones que, se suponen, vienen a renovar el cine español, a levantar su nivel creativo a la vez que propone una reflexión sobre lo que está sucediendo en esos años. La larga postguerra cinematográfica termina simbólicamente cuando se acaba la cartilla de racionamiento y comienzan a producirse una serie de películas que serán reconocidas como diferentes, alternativas al cine dominante y revolucionarias muchos años después. El espectador español que asiduamente acudía a la sala de cine buscaba películas sencillas de comprender y lineales en su tratamiento, aunque muchos ya estuvieran muy acostumbrados a las estructuras narrativas que ofrecían numerosas películas estadounidenses.

El Nuevo Cine Español -y en su caso la llamada "Escuela de Barcelona"- que emerge como necesidad de equiparar el cine patrio a lo que se está haciendo en otros países europeos, americanos o asiáticos - cosa que al ciudadano de a pie ni le preocupaba ni conocía- parece convertirse años después en "marca" de un cine realizado con intención cultural, exclusiva e internacional (Heredero, 2003; Martínez-Bretón, 1984, 2003). Lo que conviene destacar es el esfuerzo que se hace desde la Dirección General de Cinematografía para que el cine que se produce en España tenga realmente una efectiva proyección internacional, empezando por Europa. Evidentemente, muchas películas están sometidas a una temática muy española que debe ser explicada para una mejor comprensión. Esa identidad permite, especialmente, abrir nuevos territorios y llamar la atención de una generación de espectadores que irrumpe en las salas de cine con la frescura de los años y que nada, o casi nada, sabe de lo realizado anteriormente.

Se produce mucho -quizá demasiado y a bajo coste-, se distribuye fácilmente por toda la geografía nacional y el cine denominado comercial está reñido con aquel otro propiciado por el sector cultural y creativo más "inteligente". Este planteamiento industrial genera la fragmentación del espectador. La diferenciación establece unas barreras que el público no logra entender y asumir. Ciertos sectores impulsan el modelo 
renovador frente al tradicional, sin darse cuenta que la industria necesita de ambos. No hay una identidad global para el cine español, lo que plantea ya el primer enfrentamiento intencional del que saldrá un gran perjudicado: el espectador habituado a ir a la sala de cine.

Cuando en los años ochenta del siglo XX se inicia una política cinematográfica más abierta, preocupada por la calidad del cine que se hace en España, con la intención de que se hable de "cine español", de "película española", de generar un interés especial por lo que se hace en este ámbito, surge otro gran problema: se intenta acabar con el cine realizado anteriormente para pasar un capítulo de nuestra historia y abrir la mente de los espectadores contemporáneos a otras opciones creativas. Iniciativa que, sin duda, vino a ser la puntilla definitiva para acabar con el sostenimiento, vía taquilla, del cine español. Casos excepcionales reclamaban la atención de los espectadores, aunque sin que se tratara de grandes éxitos. La cuota de mercado sufría a la baja y apenas tres o cuatro títulos la sostenían. No había una identidad nacional, española, para el cine producido; y todavía menos cuando desde algunos ámbitos autonómicos se defendía la propia identidad. Tampoco había productoras que destacaran especialmente. Sin duda, todo comenzó a caminar por un sendero ya conocido: la dependencia del Estado. No se producía sin que existiera es apoyo porque las empresas no tenían recursos y no los buscaban porque resultaba mucho más sencillo que el riesgo lo asumiera el Ministerio de Cultura.

Difícilmente, se puede luchar contra algo que se quiso ignorar y que resulta que el modelo es el único capaz de sostener una industria que arriesga poco e intenta evitar su desaparición con propuestas que no dejan de ser sugerencias de cliente servil. El renombre que se va consiguiendo a nivel internacional choca directamente con el vacío y el desconocimiento que se evidencia en el mercado nacional. Esto, como no podía ser de otra manera, sorprende al más común de los mortales porque ve en primera persona cómo baja la cuota de mercado, cómo se producen películas que no se ven, cómo se presentan candidatas a los Oscar películas desconocidas por todo el mundo y cómo, desde la profesión, se introducen frecuentemente variables políticas que ayudan no solo a mantener la fragmentación sino a provocar discordia y rechazo.

La cuestión de fondo está entre lo que se quiere vender al ciudadano español, lo que se le ofrece como entretenimiento y cultura y la conquista de nuevos mercados como espacio idílico de refrendo a lo que se está haciendo. El ciudadano no entiende qué está pasando en el ámbito cinematográfico, al igual que le resulta incomprensible que el cine español sea simplemente un puñado de directores que desarrollan cada uno su línea creativa, que algunas producciones de alto coste retrasen su estreno y resulten un fiasco y, sobre todo, que se extienda la idea de rechazo permanente hacia la producción española que llega a las pantallas. Se comprende que durante muchos años el cine español se haya catalogado como género en las estanterías de los mayores centros comerciales españoles de referencia. El porqué de esta situación quizá se encuentre en que a lo largo de su historia no haya sabido proponer una idea que se mantuviera intacta en el imaginario de los españoles.

Las referencias de identificación no están lo suficientemente claras a la hora de explotar una película española, por lo cual el espectador no quiere dar bandazos y, 
como la experiencia tenida con otros estrenos no ha sido satisfactoria, busca el supuesto éxito internacional. Y cuando se acerca a una película española lo hace con un claro convencimiento de, que o bien por el director, por un actor de moda o porque un canal de televisión lo ha lanzado especialmente, debe ver dicho estreno.

Los españoles saben que se produce cine en España, que hay algunos productores que abordan diversos proyectos, que la Administración habilita mecanismos financieros para que se puedan llevar a cabo, que muchos profesionales se meten en asuntos políticos y muestran su beligerancia, que el sector en general parece que se lo monta al margen de cualquier racionalidad, que existen películas desconocidas por todo el mundo, y que apenas se habla, en general, de unas pocas.

\section{Problemas de identidad}

En el recorrido histórico del cine español se vislumbran destellos de lo que ha podido ser la identidad de una industria y la proyección de unos intereses de producción, creativos y artísticos. Hablamos de referencias, de visibilidad, de recursos que han ayudado en cada momento a establecer vínculos entre quienes ofrecían una película y aquellos a los que se dirigían.

Sin duda fueron llamativos, a nivel local, los proyectos empresariales impulsados por los pioneros en cada una de las ciudades en que vivían. Sus vecinos supieron respaldar, en buena medida, sus iniciativas (durante las primeras décadas del siglo XX desde Gelabert y Chomón en Barcelona y la casa Cuesta en Valencia, hasta la iniciativas de Atlántida en Madrid) y siguieron viendo cada uno de sus trabajos. (Lahoz Rodrigo, 2010). Sorprendió, en el caso de la productora madrileña Atlántida, que el rey Alfonso XIII adquiriera algunas acciones de la misma, aunque la presencia del monarca en el ámbito de los espectáculos y el sector inmobiliario fue notoria en el primer tercio del siglo (Martínez, 1992: 172-73), al igual que su presencia en algún estreno cinematográfico español (Sánchez Vidal, 1996: 154). Suenan al público español algunos directores pero, especialmente, los actores y actrices de teatro y cine que se convierten en iconos representativos en una cartelera que busca florecer por sí misma.

Las vinculaciones que se establecen entre el espectador y la película española parten de unos referentes sostenidos sobre la imaginería que proporciona el diseño gráfico y la fotografía. La información que contienen textual y visual son las claves para entender qué se quiere vender y cómo se articula el mensaje para que llegue con fuerza al espectador y le anime a ir al cine a ver una película. Hablamos de una primera publicidad cinematográfica que empapelaba las fachadas de las salas de cine y algunos lugares estratégicos de las ciudades.

Todavía no se manejaban todos los recursos publicitarios que se estaban diseñando en el mundo (Eguizábal, 1998: 249), y la abundancia de películas dentro de una oferta estandarizada refuerza la idea de competencia más agresiva que obligaba a desplazar el punto de atención de la producción a la exhibición, entendiendo que había que diseñar los mecanismos por los que el espectador fuera cautivado. Se articulan una serie de soportes gráficos y visuales que deben informar e ilustrar el tono de la película que se estrena (adaptación de una zarzuela, una novela muy conocida, lo que conlleva a 
destacar, en algunos casos, al propio autor -véase Alejandro Pérez Lugín-, y si es premio Nobel, mucho mejor -recordemos a Jacinto Benavente-). Algunos de los primeros ejemplos pueden ser La bejarana (1926), de Eusebio Fernández Ardavín, y Sangre y arena (1916), de Vicente Blasco Ibáñez, o El negro que tenía el alma blanca (1926), de Benito Perojo, con Conchita Piquer como reclamo. La adaptación pictórica de algún fotograma de la película o del rostro de uno de los protagonistas son las referencias utilizadas para construir el cartel. No obstante, mientras se definen los criterios, el coste y el riesgo de afrontar en su totalidad este tipo de publicidad, existen otros ejemplos como el de Sacrificio/Entre ruinas (1914), de Ricardo Baños y Alberto Marro, producción que es anunciada como gran cinedrama en tres partes, interpretado por el genial primer actor Enrique Borrás, gloria de la escena española, y de la que se da su argumento y se ofrecen diez fotografías (fotogramas) de la película, además de destacar a sus dos actrices protagonistas. Un formato que, normalmente, se utiliza en las publicaciones de la época y no tanto como cartelería. En paralelo a este modelo, en apenas una década podemos comprobar cómo se realiza un gran despliegue de medios para lanzar algunas películas como, a modo de ejemplo, La loca de la casa (1926), de Luis R. Alonso, "según la obra del glorioso D. Benito Pérez Galdós" y con la intervención protagonista de Carmen Viance; o La hermana San Sulpicio (1927), de Florián Rey, "según la obra del insigne novelista Armando Palacio Valdés, con Imperio Argentina y Ricardo Núñez".

La popularidad de los nombres y rostros artísticos son el principal reclamo, porque todavía no existen empresas de producción que hayan consolidado su marca, por mucho que encontremos en el archivo referencias visuales -logotipos- que indican qué empresa está detrás de la película (por cierto, la sala, durante algún tiempo, sí se convierte en reclamo por el interés de la programación que elabora). Sin embargo, como "propaganda" de la película -tal y como se decía en las primeras décadas y posteriormente en el argot de muchos exhibidores- se editaban los argumentos, postales y carteles en varios tamaños que se ponían a disposición del exhibidor para que pudiera dar mayor proyección al estreno que adquiría.

Cuando se acude a los fondos documentales existentes se puede descubrir, por ejemplo a través de las fotografías que se conservan, que el despliegue publicitario que se observa en las fachadas de las salas de cine de muchas ciudades españolas es sorprendente y llamativo cuando se trata del lanzamiento de una película estadounidense. Los distribuidores nacionales son conscientes de que estas películas son las que más público llevan a las salas, por lo que refuerzan en todos los sentidos la publicidad de sus títulos. Esta actividad y gestión publicitaria no se aplica, salvo casos excepcionales, a las producciones españolas. Esta historia se repetirá a lo largo de las décadas, convirtiéndose en un problema irresoluble del que todavía a día de hoy se resiente el cine español.

No obstante, a partir de los años veinte del siglo XX, desde los sectores de producción y comercialización se entiende que la película ha de tener un mínimo de alicientes que sirvan de reclamo para que hasta el ciudadano más despistado se sienta atraído por la misma. En este caso, sobre los referentes particulares de cada uno, reforzados sin duda por los soportes mediáticos, tenemos que destacar aquellos que se 
han convertido en iconos de gran valor que han proyectado la imagen de la producción española.

Cada uno puede tener en mente otros más, sin duda, pero los que vamos a mencionar sucintamente son representativos de todo un conjunto de identidades que han representado algo, mucho o poco, en la oferta y difusión del cine español tanto dentro como fuera del propio mercado. Nombres que por sí solos ya dicen mucho sobre si realmente ha existido y si todavía existe el cine español, y de la idea que tiene el ciudadano sobre lo realizado.

La identidad del cine español desde la producción está representada durante muchos años por los éxitos de Cifesa (Fanés, 1982), los triunfos de Cesáreo GonzálezSuevia Films (García Fernández, 2006) o la proyección internacional de Elías Querejeta (Hernández Les, 1986), especialmente. Los espectadores sí conocieron en cada momento a las empresas y empresarios y qué significaban las películas que ofrecían. Desde la II República y durante el franquismo también fueron reconocibles firmas como Filmófono, Orphea, Emisora-Ignacio F. Iquino, Manuel Goyanes-Guión Films, Ágata Films-José Luis Dibildos, Regia Films-Arturo González, Benito Perojo, Uninci, Epoca Films, Kalender Films, José Frade, Pedro Masó, Mariano Ozores, Balcázar, Alfredo Matas-Jet Films/Impala, Luis Megino, José Luis Garci-Nickel Odeon, Tesauro Films, Andrés Vicente Gómez, José Luis Borau-El Imán, Lauren Films, Enrique Cerezo, Gerardo Herrero-Tornasol y muchos directores, guionistas y actores convertidos en productores que van forjando el cine desde los años ochenta hasta el día de hoy (Fernando Colomo, Fernando Trueba, José Luis Cuerda-Las Producciones del Escorpión, Pedro Almodóvar-El Deseo, Alejandro Amenábar- Himenóptero y Santiago Segura-Amiguetes Entertainment). Hablamos de una oferta que va de lo popular a lo cultural, como evolución de una idea que va más allá de lo presumible en una industria como la cinematográfica.

Y no digamos nada del sector de distribución en el que muchas productoras crearon su propia división comercial y las firmas que surgen exclusivamente para esta actividad apenas pasan del logotipo que insertan en el cartel o en la presentación de la película. Recordar, a vuela pluma, entre otras, a Selecciones Huguet, Exclusivas Diana, Selecciones Fuster, Cepicsa, Ulargui Films, Emisora Films, Balet y Blay, Mercurio Films, Exclusivas Floralva, Procines, Chamartin, Mundial Films, Arturo González, CB Films, Filmax, Lotus, Filmayer, Pelimex o Izaro Films, apenas significa que el sector estaba activo, al igual que cuando surgen Musidora, Araba Films, Golem, Alta Films y otras de marcado interés independiente y vinculados al sector de exhibición y que se conocían, básicamente, en los circuitos de arte y ensayo. En la última etapa, desde Lolafilms hasta DeAPlaneta o Tripictures la actividad del sector ya está en manos, prácticamente, de las majors estadounidenses algo que, en buena medida, ya se venía produciendo desde los años veinte.

Más allá de lo meramente industrial, que ya de por sí debía tener muy definido su espacio de actuación, el público español va conociendo a alguno de los profesionales que están detrás de la cámara oficiando de directores. El prestigio de los mismos está en consonancia con la identificación que tiene el ciudadano que más frecuenta las salas de cine en cada época y que se promocionan a través de la prensa diaria y las revistas que 
se exponen en los kioscos españoles. Sin profundizar especialmente, podemos decir a modo de ejemplo que por grupos y sectores sociales los nombres de Florián Rey, Benito Perojo, Rafael Gil, Antonio Román, José Luis Sáenz de Heredia, Edgar Neville, Juan Antonio Bardem, Luis García Berlanga, Fernando Fernán Gómez, Pedro Lazaga, Ramón Torrado, Luis Buñuel, Carlos Saura, Basilio Martín Patino, Ladislao Vajda, Pedro Masó, Víctor Erice, Jesús Franco, Antonio Isasi Isasmendi, Jaime de Armiñán, Manuel Gutiérrez Aragón, Mariano Ozores, Fernando Colomo, Iván Zulueta, Pedro Almodóvar, Fernando Trueba, Julio Medem, Alejandro Amenábar y Santiago Segura, significaron algo dentro de la oferta creativa que se hizo a lo largo de un siglo de cine. Cada persona tiene sus referencias, aunque sean superficiales; esto no quiere decir que los españoles se atrevan a decir algo sobre quién ha dirigido cine a lo largo de los años. En gran medida, todo queda reducido, según con quién se hable, a cinco nombres. Las películas más taquilleras son las que, también, señalan claramente al director del proyecto, sobre todo y especialmente, en los últimos veinte años cinematográficos.

En el ámbito artístico, sin embargo, podemos encontrar un repertorio iconográfico de mayor solidez persuasiva, que sí ha marcado la evolución del cine español en todo lo que se refiere al respaldo del público. Ya hemos mencionado lo que suponían los grandes actores de la escena española para las producciones de las primeras décadas del cine. También cómo se aventuran los primeros rostros populares de la mano de Raquel Meller, Lolita París, Irene López de Heredia, Carmen Viance, Pedro Elviro "Pitouto", Enrique Borrás, Ernesto Vilches, Fortunio Bonanova o José Nieto. Durante los años treinta nadie se olvida de Imperio Argentina, Juan de Orduña, Miguel Ligero, Ricardo Núñez, Antonio Vico. La postguerra estará dominada por los grandes rostros que consiguen consolidar un star-system a la española, que popularizan el cine hasta cotas nunca vistas y se convierten en los mejores vendedores de una producción que llena las salas de cine. Así han quedado para la historia del cine español las tramas interpretadas por Amparo Rivelles con Alfredo Mayo y Rafael Durán, pero también los papeles defendidos por Manuel Luna, Luis Peña, Raúl Cancio, Antonio Casal, Carlos Muñoz, Guillermo Marín, José Isbert, Luchi Soto, Ana Mariscal, Maruchi Fresno, Conchita Montes, y un elenco de secundarios, protagonistas indiscutibles del cine español. Después van logrando más notoriedad Francisco Rabal, Fernando Rey, Fernando Fernán Gómez, Alberto Closas, Aurora Bautista, Sara Montiel, Carmen Sevilla, figuras del folklore español, niños prodigio, José Luis López Vázquez, Alfredo Landa, José Sacristán y secundarios que popularizan personajes inolvidables.

El cambio político que surge a finales de los años setenta, quiere manifestarse igualmente en la producción cinematográfica. No obstante, lo más evidente es que se repiten los mismos esquemas, aunque con otros personajes. La frescura, el contacto con la realidad, los temas polémicos y controvertidos, todo lo que emana de los grupos sociales del momento comienzan a ser representados en la pantalla para delirio de unos y rechazo de otros. El cambio actoral influye de manera decisiva no sólo en el propio sector -no se escriben papeles para actores de cierta edad- sino, también, en el cambio de espectadores. Aquellos que ya tienen una trayectoria profesional consolidada se van quedando por el camino porque nadie les atiende; porque los temas que se abordan se olvidan de ellos y sólo tienen en cuenta a sus hijos. Esta situación, igual- 
mente, acarrea notables consecuencias; la principal, que se inicia el periodo de desencuentros y desinterés del grupo mayoritario de espectadores que irá provocando una estampida que, con los años, llevará al cine español al desastre. El estrellato televisivo surgido con las jóvenes e inexpertas promesas que van apareciendo en los repartos de las series más populares, generan otro tipo de interés, el juvenil, que no deja de ser efímero porque estos nuevos rostros evidencian una falta de preparación que no parece importar a sus representantes y al sector de producción. Mientras, los actores y actrices con una mínima carrera, se sumergen en el teatro como tabla de salvación.

Más allá de las cuestiones planteadas a nivel de identificación del cine español por los ciudadanos, cabe plantearse una última referida a la proyección internacional. Al margen de los éxitos que profesionales españoles han conseguido en los más diversos eventos cinematográficos (sólo en los Oscar de la Academia de Cine Norteamérica: Luis Buñuel, Gil Parrondo, Néstor Almendros, José Luis Garci, Fernando Trueba, Pedro Almodóvar, Javier Bardem, Alejandro Amenábar o Penélope Cruz) el público español quiere comprender por qué sucede esto cuando en el propio mercado sus trabajos, salvo excepciones, no consiguen igual repercusión o plantean todo tipo de discusiones. El desentendimiento existente entre público y producción se manifiesta en que gran parte de la producción española no se ve o llega en malas condiciones a las salas de proyección. Además, por la implicación de los profesionales en las actividades de determinados partidos políticos y en las manifestaciones llevadas a cabo contra el Gobierno de José María Aznar, algo que ha hecho mucho daño a su propio trabajo. Podemos recordar en este sentido que el "no a la guerra" cuando España participa en la invasión de Irak en 2003, o "hay motivo" para denunciar la realidad política y social española en 2004, son ejemplos evidentes. Sobre la película ;Hay motivo! Se puede leer en la sinopsis que aparece en la Web del ICAA, "Esta es una película de largo metraje hecha de 33 pequeñas piezas, de alrededor de tres minutos de duración, más un epílogo. Cada una de las piezas está dirigida por un director distinto y tiene por objeto denunciar algún aspecto de la realidad política y social española que se vio especialmente deteriorada durante la Legislatura de 2000 a 2004. En "¡Hay motivo!" nos animó el derecho legítimo a la libre expresión, quisimos abrir los ojos de los ciudadanos y mostrar algunos problemas que el Ejecutivo de los últimos años desatendió, manipuló, obvió o directamente escamoteó a la opinión pública".

El silencio social, popular y artístico se mantiene durante el gobierno socialista dirigido por José Luis Rodríguez Zapatero. Un ejemplo evidente lo encontramos con la aparición en sociedad del "movimiento 15M" que mientras estuvieron los socialistas en el poder ningún profesional del cine dio muestras de simpatía hacia tal iniciativa. Tras acceder a la presidencia del Gobierno de España, Mariano Rajoy, unos meses después se deja ver Pedro Almodóvar en la Puerta del Sol madrileña, manifestando a la prensa: "Bueno, yo simpatizo con ellos, me siento muy cercano. Esto le viene muy bien a la izquierda. Algo se mueve en la mejor dirección, aunque no se sepa cuál es, porque ellos ni son políticos ni tienen capacidad de hacer leyes" ("El Mundo", 14-5-2012).

Estas actitudes, iniciativas, argumentos y posturas en donde se entremezclan opiniones personales con una actividad con proyección social, no sólo confunden a los ciudadanos sino que les llevan a tomar posiciones sobre el ejercicio profesional que 
desarrollan los implicados. Y esta imagen, sin duda, no sólo les ha perjudicado, sino que ha deteriorado en gran medida la percepción que el público español tiene de su trabajo para el cine y el teatro, incrementando los problemas de identidad, reconocimiento y defensa de una profesión que busca sostenerse del erario público.

\section{Difusión de la Imagen}

La industria cinematográfica mundial no existiría sin el apoyo que le ha proporcionado el mundo de la comunicación en general (prensa, radio, televisión, video, Internet). Desde sus primeros pasos contó con la colaboración de las revistas de información cinematográfica que, más allá de la prensa diaria, fueron apareciendo en todo el mundo. En cada país comenzaron editándose un buen número de cabeceras que buscaban difundir regularmente las noticias más relevantes de la industria, la interpretación, el ambiente social y artístico en el que se movían las estrellas propias y ajenas. Eran auténticos altavoces del día a día de los Estudios de rodaje, del ambiente familiar de los protagonistas y de todo aquello que pudieran promocionar los rostros más relevantes del firmamento estelar. El público, especialmente el femenino en un primer momento (Montero y Paz, 2002: 91), tomaba contacto con los futuros estrenos a través de las páginas ilustradas, con grandes titulares y referencias publicitarias que seducían a través de la elegancia de los actores y actrices, convertidos en escaparate del cine.

La maquinaria industrial de un negocio que promueve miles de películas al año tiene que hacerse notar, además ha de sacar el máximo rendimiento a todo lo que genera y proyecta en el corto y medio plazo. Desde cualquier origen, las películas que circulan por el mundo quieren llegar con igual fuerza a todos los países; cada etapa está dominada por un lugar de origen, pero en el fondo será la poderosa maquinaria hollywoodiense la que acabe por imponerse al resto, quizá porque es consciente de que el sector industrial está bastante mejor consolidado que el de otras naciones.

El modelo de revista estadounidense también se aplica en el resto del mundo. Las publicaciones españolas hablan de todos los temas en general: en qué momento se encuentra una producción, qué papel interpretan los principales protagonistas, quién es el director y el Estudio que impulsan el proyecto; es decir, de los rodajes, de los estrenos y de cómo es la vida de tal actriz o actor.

Ya desde los años treinta en España se abre una vía al análisis y la interpretación cinematográfica que busca a los espectadores más interesados en el cine como arte que como entretenimiento. Estas posturas reflejan otras más ideológicas que exigen no quedar impasible ante lo que se pueda ver en una sala de cine. Para estas publicaciones, no toda la producción es válida. Hay que ser inteligente y saber elegir. El problema principal es que fueron reducto de una cultura cinematográfica con poca proyección, la que podía tener el mundillo en el que se movían los propios críticos y estudiosos.

Precisamente desde este ámbito, en todas las épocas, se inician campañas para reforzar el interés por las nuevas formas de narrar que ofrecen los jóvenes directores que llegan a la industria cinematográfica. En el fondo de las cuestiones y debates que se plantean está en cómo acabar con el cine "comercial", en el sentido de desprestigio social. Claro que estos críticos se olvidan, al igual que los creadores, que hay un público masivo que tiene otras prioridades a la hora de ver una película. Este 
enfrentamiento se irá agudizando con el tiempo, algo que se sabe desde ámbitos estadounidenses y se fomenta, porque saben que de antemano lo que proponen está realmente acabado; sobre todo, desde la perspectiva que defienden.

La radio y la televisión son utilizadas para dar publicidad a los estrenos, y los programas culturales en los que se habla de cine intentan abordar todo lo que se ofrece semanalmente. Cine popular, cinefilia; todo va teniendo cabida en la programación de TVE. Después los canales privados incluirán en franjas horarias determinadas un hueco para el cine. Más adelante la multiplicación de la oferta generará más contratos y dará paso a emisiones reiterativas. Algunos canales darán huecos a programas específicos de cine, mientras que la única empresa que mantendrá activa una oferta diversificada será TVE en sus dos canales principales.

La información, los comentarios, la crítica, la difusión de avances (tráiler), promociones, imágenes de todo tipo, las entrevistas a profesionales de cualquier época, los making-of o la difusión de los festivales, son parte fundamental de la existencia de los medios de comunicación y programas audiovisuales especializados. Sin embargo, según fueron apareciendo más medios o soportes más apreciable fue la pérdida de independencia comunicativa.

Bien, pero lo dicho hasta ahora no deja de ser un planteamiento generalista en el que el cine español no tiene mucha cabida. De entrada, porque los medios de comunicación en general dan muchos más espacio a los estrenos norteamericanos; después, porque el crítico o informador cinematográfico va dejando huellas sobre qué es lo que le interesa o apasiona, con lo que condiciona su trabajo y, consecuentemente, la lectura que hace el posible espectador del mismo; por último, porque existe un prejuicio notable frente al trabajo del profesional español estigmatizado desde la crítica. Todo esto lo percibe el público español y, tras sucesivas experiencias vitales, son menos los que se dejan seducir por opiniones manifiestamente personales.

Los medios han jugado un papel fundamental en la difusión del cine. Siguen teniendo una notable influencia, pero el sector ha estado, históricamente, demasiado condicionado por las imposiciones del mercado -las majors-, al margen de la influencia social -que también impregna al crítico- y popularidad que ha demostrado tener el cine norteamericano "favorecido por su estilo narrativo universal, el atractivo de su star-system, la internacionalización del mercado [y su control] y el empleo de gigantescas campañas de marketing" (Pardo, 2005: 162).

En el fondo de esta cuestión general se encuentra el problema del cine español: ¿Tiene imagen el cine español? ¿Cómo se difunde? ¿Quiénes son los portavoces que asumen la decisión de indicar qué es lo esencial? ¿Hacia qué público se dirigen las acciones? ¿Con qué argumentos se pretende convencerle? Y como reflexión básica ¿realmente se conoce el cine español? No se puede mirar para otro lado y buscar culpables de una situación que se ha creado dentro de un país (es evidente que comparar el cine español que se siempre se ha visto con el cine americano que se ha exhibido no tiene sentido; el espectador, en su mayoría, siempre se ha dejado atrapar por el cine que llegaba de Hollywood porque era muy bueno).

Hubo tiempos en los últimos cien años en que el cine español fue reconocido, identificado, aplaudido y seguido con gran interés. Se celebraban sus éxitos y se apoyaba 
consciente o inconscientemente porque ofrecía un interés evidente. Hay signos palpables de que la producción nacional se veía a lo largo de todo el territorio, llegaba a cualquier rincón de la geografía española, superando las mil dificultades a través de una red de comercialización que jamás se ha vuelto a tener en España. El cine español era visto por un amplio sector de espectadores; el cine español era conocido en su inmensa mayoría que, sorprendentemente, hablaba de los nuevos estrenos. Y todo desde la convivencia más simple. Pero pronto llegaron aquellos que rompieron esa convivencia, defendiendo posturas supuestamente más creativas pensando mejorar el nivel cultural de los españoles. Y, en lugar de hacerlo desde el entendimiento, se arrogaron un espíritu autoritario, supuestamente democrático, de 'o estás conmigo o contra mi'. Arrogancia intelectual que fragmentó, inevitablemente, cualquier posibilidad de que dos ideas de entender el cine pudieran caminar a la par.

José María García Escudero, en dos ocasiones director general de cinematografía, llegó a dejar escrito que el cine español comenzó en 1939. Años más tarde, el director Juan Antonio Bardem se reafirmó en que el cine español realmente existe desde los años cincuenta. Treinta años después, la directora Pilar Miró, como directora general de cinematografía, desarrolló unas normas que, aplicadas, acabaron con la industria, el negocio y la taquilla del cine español. En la actualidad, ya nadie se pronuncia sobre lo realizado anteriormente porque, el problema principal, se centra en la subsistencia de la industria audiovisual.

\section{Conciencia de marca. Un objetivo necesario}

La subsistencia de un sector está directamente relacionada con la aceptación que genera en la sociedad. Ésta manifiesta su nivel de aceptación (o rechazo) en función de lo que le ofrece o, para hablar con rigor, de la percepción que tiene de lo que le ofrece. Por decirlo en términos de mercado: si en opinión del público, sus productos no gustan o el precio genera rechazo o es negativa la imagen que tiene de lo que hace o representa, el sector en cuestión tiene ante sí el reto de solventarlo. Y debe solventarlo desde dentro, ésta es la postura madura que permite disponer de la independencia que luego siempre se reclama.

Trabajar para que el público elija ver cine español es un objetivo necesario. Abordarlo partiendo de una visión consensuada entre los que tienen responsabilidad en ello es imprescindible y conlleva, por una parte, trabajar para un posicionamiento (Hernández, 1999: 124; Trout, 2010: 17) y, por otra, diseñar un plan estratégico. El cine español compite, con otras producciones y otras opciones de ocio y entretenimiento. En multitud de sectores se actúa sabiendo que la elección de otras opciones por parte del público supone, más tarde o más temprano, desaparecer o, en el mejor de los casos, perder recurrentemente la oportunidad de estar en una mejor situación.

A menudo se habla de la mala salud de hierro de algunos sectores que forman parte de la industria cultural, de una crisis permanente en la que siguen ofreciendo creatividad, innovación y muestra de altos niveles de calidad, muchas veces premiada en los eventos creados por el propio sector (premios Goya, Max, etc.). Como si se tratara de un mal imposible de eliminar se discute sobre ello al tiempo que se consigue dinero, a veces in extremis, para que algunos proyectos salgan adelante. En la búsqueda de 
presupuesto se llama a las puertas de la Administración, las televisiones y la de otros sectores empresariales.

En este sentido, desde un punto de vista empresarial, de comunicación estratégica y de marketing, el sector cinematográfico -industria cinematográfica- es una rara avis. Y lo es, al menos, por dos razones. La primera, por sus fuentes y sus argumentos a la hora de buscar financiación. ¿Por qué darles dinero para que se produzcan sus películas? Las Administraciones pueden interesarse en la medida que financian determinada oferta cultural, aunque su preocupación principal debe estar en los servicios públicos, ¿éste lo es?; las televisiones forman parte de sector audiovisual, emiten cine -y series- $y$ pueden obtener prestigio si la producción en la que han participado recibe premios; por su parte, las empresas de otros sectores pueden ver en las películas un soporte para la difusión de sus marcas.

Frente al conjunto de empresas que deben vender su producto para seguir en el mercado, en éste el público podría no ser una prioridad. Ésta es la segunda razón: es, como ya hemos señalado, una rara avis empresarialmente hablando, porque es un sector que no parece preocupado por acertar con su oferta. Las películas pueden no ser rentables en taquilla (o en otras pantallas), pero se sigue haciendo cine. ¿ROI? ...qué es el $R O I^{3}$ preguntaba al de al lado alguien de cine escuchando una conferencia.

El cine es por definición un sector privado, sin embargo no busca financiación principalmente en la aceptación de los productos que ofrece. Si un producto no tiene la suficiente aceptación, no se vende y no genera ingresos por sí mismo, se debería trabajar en ello. Una empresa, una industria, debe ser rentable o dependerá de las subvenciones. Si se depende del dinero público, se plantean otras cuestiones.

Para que surjan películas de calidad es necesario que la producción aumente. Si hay muchas películas al año la probabilidad de contar con un número mayor de buenas producciones crece. A veces el público no está preparado para determinado cine... Estas son afirmaciones que representan una de las mentalidades del sector cinematográfico. Se dan por normales, pero son extrañas. Sería interesante escuchar la opinión de empresarios de otros sectores. ¿Quién se puede permitir producir mucho para que salga algo bueno, o invertir en productos o servicios para los que el público no está preparado? Seguramente es una cuestión de financiación, si se tiene el dinero para hacerlo repetidamente no importará tanto.

La financiación es vital, para conseguirla sería lógico buscar el apoyo del público, para lograrla hace falta el producto y posicionamiento. ¿Se hace el cine que quiere el público? o ¿se trabaja al menos en que quiera el cine que se hace? Una vez hecho el análisis histórico que explica la situación actual, es preciso abordar estas dos preguntas, ambas son el punto de partida ya que ponen el foco de atención en el público.

Las galas de los Goya reivindican de forma notoria el valor de nuestro cine pero no es suficiente con que llegue el mensaje una vez al año. No se puede pretender que un país entero se sienta orgulloso de sus productos, que los compre, los recomiende y admire todo lo que tiene que ver con sus protagonistas $\mathrm{y}$, sin embargo, siga sin incor-

3 Return On Investment o índice de retorno sobre la inversión, se trata de un porcentaje que refleja la relación entre la inversión realizada y los beneficios obtenidos. 
porar principios elementales de disciplinas como la gestión de marca, la comunicación estratégica y el marketing. Contarle a la sociedad que son necesarias las subvenciones y que lo que se recibe es poco parece ser el mensaje más recurrente. Quizás el público no esté de acuerdo con ello pero, incluso los convencidos, poco pueden hacer para apoyarlo. Es preciso enviar al público otros mensajes. Urge comprender que no se gana al público diciéndole, principalmente, que esta industria necesita apoyo y subvenciones.

Ninguna marca líder ha conseguido serlo haciendo esto. Como señala Southgate "Las marcas no pertenecen al fabricante. Pertenecen al consumidor" (1997: 24). Ellas ofrecen algo a un tipo de personas que responde a lo que necesitan y desean, les recuerdan en qué se diferencian y se presentan como parte de sus vidas.

La marca, cuando lo logra, vincula lo que ofrece a lo que es importante para los que la eligen, no sólo en el aspecto tangible respondiendo a la necesidad que cubre y a sus preferencias, sino a sus valores y su forma de vida. En el mejor de los casos pasa a convertirse en un símbolo de un grupo social, una comunidad o un país. ¿Acaso Hollywood no encaja en esta descripción? La consecuencia es la fidelidad, que no siempre es a prueba de imposibles, pero que crea a veces, durante muchos años, una barrera ante los ofrecimientos de otras marcas.

La marca se compone de una identidad materializada en un nombre y su representación visual, la afirmación de un posicionamiento o valor que define y diferencia al producto (Trout, 2011: 17) de cualquier otra oferta en competencia y la imagen de marca, que representa el significado que tiene para el público (Koch, 1994). El posicionamiento o valor principal reconocido a la marca es una de las decisiones más comprometidas. Se trata de una elección estratégica que deriva de las necesidades o deseos de su público, los atributos del producto y el mercado (Hernández, 1999: 128) definido por unas condiciones y una competencia directa y, en ocasiones, también indirecta.

Puede tratarse de un posicionamiento basado en atributos del producto, la relación calidad/precio, el uso o aplicación, el público al que se dirige, la categoría a la que pertenece el producto, el símbolo cultural que representa o su relación con la competencia (Aaker y Myers, 1984: 260).

Muchas empresas han incorporado a sus organigramas el área y/o responsable de gestión de marca, conscientes de la prioridad de sus funciones, que son esencialmente identificar, diferenciar y hacer apreciable lo que ofrecen. Comunicarse con los públicos de la marca y alimentar su seguridad a la hora de elegirla es una meta que se traduce en la planificación de la comunicación tanto comercial como corporativa. A grandes rasgos, el proceso de branding consiste en: $1^{\text {a }}$ Definir la identidad de la marca: su posicionamiento y sistema de valores contextual, denominación e identidad visual. $2^{\mathrm{a}}$ Gestionar la marca en su entorno competitivo a fin de que llegue al público para el que se ha creado: comunicación del lanzamiento, distribución y atención en punto de venta. $3^{\text {a }}$ Seguimiento, evaluación y actualización de la marca en función de los cambios de la compañía, el producto y la sociedad: innovación y reposicionamiento.

La industria cinematográfica está a tiempo de trabajar su identidad para construir una imagen positiva y diferente que el público sepa explicar con las mismas palabras que la industria elija. Para esto es preciso definirse y comunicar a la sociedad/mercado 
su promesa (Brujó, 2010: 81) y solo podrá resultar convincente si trata de cumplir esa promesa; esto es, de ser coherente con el mensaje dado. Tal definición, directamente relacionada con el concepto clásico de posicionamiento (lugar que ocupa nuestro cine en la razón y la emoción de los públicos), es más compleja de resolver y de cumplir cuando se trata de una marca sectorial y ligada a un territorio amplio y diverso. La comunicación derivaría en sucesivas campañas genéricas que requieren un consenso amplio por parte de los implicados.

Tampoco sería el primer sector implicado en defender conjuntamente sus intereses y tratar de ajustar la oferta a la demanda. La comunicación en este aspecto puede marcar la diferencia respecto a cualquier etapa anterior. El sector será más fuerte en la medida que sea capaz de llegar a la sociedad. Nadie le niega al cine ser un referente en creatividad, pero en lo que se refiere a su promoción no rompe la línea que ha seguido durante décadas y décadas, ni siquiera para anunciar las películas. Por ejemplo, los carteles de cine, la publicidad gráfica, los trailers, las presentaciones a prensa siguen repitiendo el mismo esquema, casi sin excepción. Se puede reposicionar el cine español, se puede gestionar como marca, se puede crear un plan estratégico de comunicación, se puede ser más creativo a la hora de dar publicidad de las películas, la producción española puede alcanzar mayor notoriedad. Requiere tiempo y supone un riesgo (Haig, 2004:15) puesto que significa innovar en la relación con la forma de estar en la sociedad, pero si no se da el paso será difícil generar cambios.

Tener una imagen definida y positiva del cine español es posible. Que una mayoría sienta un vínculo fuerte con lo que representa, también. Por eso hablamos de reposicionar (Trout, 2011), es decir, de ajustar las percepciones que tienen los diferentes públicos acerca de la producción y del sector cinematográfico. Precisamente por ello hay que vigilar la coherencia de los mensajes con las películas y el comportamiento del sector y planificar una comunicación eficaz. No se trata de que las películas gusten a todos -cada público elegirá las suyas-, sino de eliminar barreras que están en nuestro consciente y subconsciente. Las cifras cuentan una y otra vez que el cine español gusta con reservas, se sabe que ha existido y existe una etiqueta sobre nuestra industria de la que cuelgan adjetivos no siempre favorables. Una reflexión sobre la combinación de estas dos circunstancias lleva a pensar en la posibilidad de trabajar en el terreno de las percepciones.

El siguiente decálogo sobre cómo son las marcas líderes explica lo que representa, en términos de preferencia, una marca para el público:

1. Representan un valor principal que se han ganado entre un público determinado. Para ese público la marca es sinónimo y representación de ese valor.

2. Han creado una serie de asociaciones positivas que afianzan su identidad y refuerzan al público a la hora de mostrarse partidarios de ella.

3. No se confunden con ninguna otra marca, son diferentes. Otros productos que también son accesibles para su público no tienen lo que $s u$ marca tiene o es.

4. Tiene conocedores, partidarios, convencidos, defensores y no sólo consumidores.

5. Ha construido un vínculo, el público que la elige considera que forma parte de su mundo, de su propia historia. 
6. Ha creado un discurso que encaja en su forma de vida, no sólo no le es ajeno sino que habla de él. Marca e individuo o grupo hablan el mismo lenguaje.

7. Han sabido evolucionar, son dinámicas y se mueven en función de los cambios del mundo al que pertenecen. No se pueden quedar anticuadas.

8. Representan una opción una forma de ver la vida y de actuar. Quienes utilizan, comen o llevan esa marca forman parte de un tipo de personas con ciertas preferencias, incluso valores y hábitos. La marca es una de las señas de identidad de ese grupo de pertenencia.

9. Los que eligen esa marca se sienten orgullosos de ella, no ocultan su consumo o su voto. Tienen argumentos para explicarse y explicarla.

10. Trabajan para mantener su posición, esto es, la fidelidad ganada. Saben que tienen que cumplir su promesa en el tiempo, ser creíbles y coherentes en el nivel de calidad-precio del producto, de servicio y de reputación corporativa.

Cuando escuchamos fuimos a ver una película española o esta noche ponen una española se está reflejando una imagen. El público tiene una imagen del cine español, incluso los que no ven su oferta. Influyen en esta percepción el producto, la distribución y la percepción que se tiene de sus actores, así como de un reducido número de directores.

Hay que analizar las debilidades, fortalezas, amenazas y oportunidades y preguntarse qué quiere el público. ¿Quiere verse retratado, quiere evadirse, qué le da otro cine...? Cuando decimos público, ¿cuántos públicos existen? Cuándo en cualquier sociedad (y mercado, están juntos) se ofrecen productos diferentes adaptados a las necesidades/deseos de cada segmento. ¿Segmenta el cine español? ¿Crea teniendo en cuenta lo que va a gustar? ¿Acaso querer gustar al público globalmente hablando es un objetivo razonable?

Estas preguntas forman parte de una manera de trabajar sectorialmente. Si se actúa estratégicamente los resultados de aceptación pueden cambiar. ¿Qué queremos para nuestro cine? Quizá haya que empezar por el principio, es decir, por definir los objetivos a corto, medio y largo plazo. Cualquier sector necesita individualidades pero se ve enormemente beneficiado si se trabaja de forma estratégica y conjunta. Efectivamente es una tarea complicada, por eso en muchos casos sólo se lleva a cabo como consecuencia de una situación de amenaza. Exige en concreto la existencia de una entidad que represente a los diferentes intereses y una cabeza visible con capacidad de liderar la ejecución del plan estratégico.

Vivimos en una época de cambio estructural, un cierre de ciclo que ha multiplicado el nivel de incertidumbre y rebajado sensiblemente los niveles de bienestar social de la llamada clase media. Nuevos hábitos, menos renta, más tecnología que potencia el consumo individual de contenidos audiovisuales, del acceso a los medios, los productos culturales y el entretenimiento. En este contexto tanto las individualidades como el sector en conjunto deben buscar oportunidades (RIES y RIES, 2005: 17) y demostrar la capacidad de liderar una nueva etapa para el cine español.

En síntesis, nuestra investigación plantea: 
- Definirse, crear y gestionar la marca cine español y contar con la comunicación desde una mentalidad estratégica. Estos son objetivos necesarios si se quieren obtener mejores resultados. No obstante, hay que reconocer que la definición estratégica de la marca en el caso del cine español supone un ejercicio complejo.

- La sensación de crisis del sector parece irremediablemente unida a él. La etiqueta cine español se utiliza principalmente para pedir. Se pide al mundo de la cultura, reconocimiento; a las Administraciones, dinero; y al público, que vaya a las salas. En este sentido se han dado algunos pasos relevantes pero no se ha abordado un plan estratégico global ni se han integrado los mensajes.

- Es preciso previamente preguntarse: el producto ¿se ajusta a lo que quieren los públicos?, la percepción real del público ¿es la adecuada?, la distribución ¿facilita al máximo el acceso al producto?

- Un planteamiento estratégico exige tomar decisiones sobre lo que podemos entender por "público español" y a quién o quiénes es lógico dirigirse. Tanto el público real -el que va al cine o elige en qué pantalla verlo-, como el potencial, es variopinto. El público de un producto cuyo rasgo común elemental es su país de nacimiento debe ser analizado cuidadosamente, sin perdernos en los significados de "ser español", ni caer en la tentación de temer lo peor en el caso de España.

- Nuestro cine puede ser identificado y preferido de una forma más positiva, es posible saber contar lo que ofrecemos y potenciar la posibilidad de ser identificado como algo positivo, diferente y deseable.

- La innovación en la elección de las acciones de comunicación puede actuar a favor. No se trata de despreciar las acciones tradicionales, ellas son creadoras de marca y la demostración de que se pueden alcanzar objetivos relevantes. El cartel de cine es un clásico muy apreciado, los festivales representan un gran esfuerzo por dar a conocer y reconocer la producción cinematográfica de los directores españoles, los tráilers son un estímulo para la audiencia, pero a menudo están diseñados desde la mirada de la profesión, no del público.

- La evaluación de la marca y la imagen de marca es también una herramienta eficaz, si lo que se implanta es un verdadero plan estratégico debe estar incluido al final del mismo.

\section{Conclusiones}

El cine español ha tenido una historia rica en aportaciones notables y excelentes más allá de lo que gran parte del público español dice reconocer. El problema que ha derivado en esta apreciación se encuentra en el desconocimiento que se tiene de la producción realizada a lo largo del tiempo.

El público español conectó con su cine en muchas etapas de su vida, siempre entendiendo que las historias que se proyectaban en las salas les permitían divertirse, soñar o entretenerse.

Con estas referencias se ha comprobado que la percepción del cine español es muy diferente según quien atienda a qué producciones y en qué momento de la historia. El punto de partida, no obstante, se encuentra en el productor y director, en qué proyec- 
tos han llevado a cabo y con qué intenciones. Después se puede valorar la recepción manifiesta hacia esas obras, la normativa elaborada desde la Administración del Estado y las consecuencias de la misma en la consolidación de la industria, del mercado y su continuidad en el tiempo.

La producción cinematográfica española en los últimos treinta años se ha enfrentado a sí misma, ha sobrevivido a las eventuales circunstancias que se le fueron presentando sin buscar soluciones reales que le permitieran afrontar el futuro con solvencia y notoriedad. Se ha preocupado más de que los recursos inmediatos -el proteccionismo público- no le faltaran en vez de pensar que debían consolidar una imagen de marca, necesaria en los tiempos que corren y fundamental en el mundo del audiovisual.

El público se ha distanciado paulatinamente porque desde hace varias décadas nadie piensa en él. Se decanta por otras cinematografías porque en ellas encuentra lo que realmente le interesa. Pero, en el fondo de todo esto, se aprecia que la postura adoptada deviene, especialmente, del desconocimiento que se tiene de la oferta anual y del poco interés manifiesto por los profesionales de difundir el trabajo realizado.

La internacionalización es importante, pero todavía más el reforzar el interés por el producto propio en el público español. Para que el cine forme parte de la cultura española hay que difundirlo adecuadamente y que pueda ser conocido por todos.

El público, los profesionales, las asociaciones e instituciones implicadas deben esforzarse en impulsar un proyecto conjunto, única garantía de un futuro más favorable. Y para ello han de contemplar todo tipo de aportaciones y su difusión en los soportes tecnológicos existentes y futuros, porque estar al día permite abrir puertas por las cuales comunicar lo realizado. Y todo ello a través de una imagen propia, una marca que consolide un proyecto conjunto y que sea respaldado activamente por todos.

\section{Referencias bibliográficas}

AAKER, David A. y MYERS, John G. (1984): Management de la publicidad. Barcelona, Hispano Europea. Vol. II.

BRUJÓ, Gonzalo (2010): En clave de marcas. Madrid, LID Editorial.

CRAINER, Stuart (1997): El verdadero poder de las marcas. Madrid, Eresma \& Celeste.

EGUIZÁBAL, Raúl (1998): Historia de la publicidad. Madrid. Editorial Eresma \& Celeste Ediciones.

FANÉS, Félix (1982): Cifesa, la antorcha de los éxitos. Valencia, Institución Alfonso el Magnánimo.

FERNÁNDEZ COLORADO, Luis y CERDÁN, Josetxo (2007): Ricardo Urgoiti. Los trabajos y los días. Madrid. Filmoteca Española/ICAA/Ministerio de Cultura.

FERNÁNDEZ HEREDERO, Carlos (2003): "En la estela de la modernidad", en FERNÁNDEZ HEREDERO, Carlos y MONTERDE, José E.: Los "nuevos cines" en España. Ilusiones y desencantos de los años sesenta. Valencia. Institut Valencià de Cinematografía-Ricardo Muñoz Suay. 
GALÁN, Diego (1997): "El cine español de los años cuarenta", en GUBERN, R. (Coord.): Un siglo de cine español. Madrid. Academia de las Artes y las Ciencias Cinematográficas de España. Cuaderno ${ }^{\circ} 1$.

GARCÍA FERNÁNDEZ, Emilio C. (2006): "Las estrellas de Cesáreo González”. Revista AGR. N 32.

GARCÍA FERNÁNDEZ, Emilio C. (2004): "La fragilidad comunicativa del cine español", en BENAVIDES, Juan et al.: Información, producción y creatividad en la comunicación. Madrid. Fundación General de la Universidad Complutense.

GARCÍA FERNÁNDEZ, Emilio C. (2003): “Cesáreo González, el hombre que paseó por el mundo al cine español". Revista AGR. Año IV. N 19.

GARCÍA FERNÁNDEZ, Emilio C. (2002): El cine español entre 1896 y 1939. Historia, industria, filmografia y documentos. Barcelona, Ariel.

GARCÍA FERNÁNDEZ, Emilio C. (1985): Historia ilustrada del cine español. Madrid. Planeta

GUBACK, Thomas H. (1980): La industria internacional del cine. Madrid, Fundamentos. 2 vols.

GUBERN, Roman (1977): El cine sonoro en la II República. 1929-1936. Madrid, Editorial Lumen.

HAIG, Matt (2006): El reinado de las marcas. Barcelona, Gestión 2000.

HERNÁNDEZ MARTÍNEZ, Caridad (1999): Manual de creatividad publicitaria. Madrid, Síntesis.

HERNÁNDEZ LES, Juan (1986): El cine de Elías Querejeta, un productor singular. Bilbao, Ediciones Mensajero.

KOCH, Richard (1994): The Financial Times. A-Z Management and Finance. London, Pitman.

LAHOZ RODRIGO, Juan I. (2010): A propósito de Cuesta. Escritos sobre los comienzos del cine español 1896-1920. Valencia. Ediciones de la Filmoteca.

MARTÍNEZ, Josefina (1992): Los primeros veinticinco años de cine en Madrid 18961920. Madrid, Filmoteca Española/Consorcio Madrid 92.

MARTÍNEZ-BRETÓN, Juan A. (2003): "La Escuela de Barcelona. Desde un contexto histórico", en FERNÁNDEZ HEREDERO, Carlos y MONTERDE, José E.: Los "nuevos cines" en España. Ilusiones y desencantos de los años sesenta. Valencia, Institut Valencià de Cinematografía-Ricardo Muñoz Suay.

MARTÍNEZ-BRETÓN, Juan A. (1984): La denominada 'Escuela de Barcelona. Madrid, Universidad Complutense. Tesis Doctoral.

MONTERO, Julio y CABEZA, José (Eds., 2005): Por el precio de una entrada. Madrid, Ediciones Rialp. 
MONTERO, Julio y PAZ, María Antonia (2002): "Ir al cine en España en el primer tercio del siglo XX”, en PELAZ, José V. y RUEDA, José C. (Eds.): Ver cine. Los públicos cinematográficos en el siglo XX. Madrid, Ediciones Rialp.

MONTERO, Julio y PAZ, María Antonia (2011): Lo que el viento no se llevó. Madrid, Ediciones Rialp.

PARDO, Alejandro (2005): "Globalización y Americanización: Nuevos frentes en la batalla económica y cultural entre Hollywood y Europa", en MONTERO, Julio y CABEZA, José (Eds.): Por el precio de una entrada. Madrid. Ediciones Rialp.

PAZ, María Antonia y MONTERO, Julio (2010): "Las películas censuradas durante la Segunda República. Valores y temores de la sociedad republicana española (1931-1936)". Estudios sobre el Mensaje Periodístico. Vol. 16, pp. 369-393. Madrid, Servicio de Publicaciones de la Universidad Complutense.

PELÁZ, José V. y RUEDA, José C. (Eds., 2002): Ver cine. Los públicos cinematográficos en el siglo XX. Madrid, Ediciones Rialp.

RIES, Al y RIES, Laura (2005): El origen de las marcas. Barcelona. Urano.

SÁNCHEZ VIDAL, Agustín (1996): El siglo e la luz. Aproximaciones a una cartelera. I. Del Kinetógrafo a Casablanca (1896-1946). Zaragoza, Caja de Ahorros de la Inmaculada de Aragón.

SOUTHGATE, Colin (1997): "Las marcas no pertenecen al fabricante. Pertenecen al consumidor", en CRAINER, Stuart: El verdadero poder de las marcas. Madrid, Eresma \& Celeste.

TROUT, Jack (2010): Reposicionamiento. Madrid, Pirámide.

VARGAS LLOSA, Mario (2012): La civilización del espectáculo. Madrid, Alfaguara.

* Este trabajo se ha realizado en el ámbito del Proyecto de Investigación I+D+i “La imagen de marca del cine español" (CSO2011-24622). Ministerio de Economía y Competitividad. Gobierno de España. 